This manuscript is a preprint and has not yet been submitted for publication. Subsequent versions of this manuscript may have slightly different content. Please feel free to contact any of the authors with feedback. 


\title{
Variability of headwater stream network extents controlled by flow regime and network hydraulic scaling
}

\author{
DA Lapides ${ }^{1}$, CD Leclerc ${ }^{1}, \mathrm{H} \mathrm{Moidu}^{2}$, DN Dralle ${ }^{3}$, and WJ Hahm ${ }^{1}$ \\ ${ }^{1}$ Department of Geography, Simon Fraser University, Burnaby, BC, Canada \\ ${ }^{2}$ Department of Environmental Science, Policy, and Management, University of California-Berkeley, Berkeley, CA, USA \\ ${ }^{3}$ Pacific Southwest Research Station, United States Forest Service, Davis, CA, USA
}

Correspondence: Dana A Lapides (danalapides@gmail.com)

Abstract. Stream networks expand and contract through time, impacting chemical export, aquatic ecosystem habitat, and water

5 quality. Although recent advances improve prediction of the extent of the wetted channel network $(L)$ based on discharge at the catchment outlet $(Q)$, controls on the temporal variability of $L$ remain poorly understood and unquantified. Here we develop a quantitative, conceptual framework to explore how flow regime and stream network hydraulic scaling factors co-determine the relative temporal variability in $L$. Network hydraulic scaling determines how much $L$ changes for a change in $Q$, while the flow regime describes how $Q$ changes in time. We compiled datasets of co-located dynamic stream extent mapping and discharge to analyze all globally available empirical data using the presented framework. We found that although variability in $L$ is universally dampened relative to variability in $Q$ (i.e., streamflow is relatively more variable in time than network extent), the relationship is elastic, meaning that for a given increase in the variability in $Q$, headwater catchments will experience greaterthan-proportional increases in the variability of $L$. Thus, under anticipated climatic shifts towards more volatile precipitation, relative variability in headwater stream network extents can be expected to increase even more than the relative variability of discharge itself. Comparison between network extents inferred from the L-Q relationship and USGS topographic maps shows widespread underestimation of the wetted channel network by the mapped extent of both perennial and dynamic stream extents. Keywords: wetted channels, stream network extent, flow regime, network hydraulic scaling, hydrograph variability, aquatic ecosystem habitat, hydrography, perennial streams, intermittent streams

\section{Introduction}

Headwater stream discharge and network extent—and their variability in time-impact aquatic ecosystem habitat, carbon dioxide efflux, stream temperature, water transit times, and legal frameworks that define river corridors (e.g., Acuña et al., 2005; Allen and Pavelsky, 2018; Arismendi et al., 2017; van Meerveld et al., 2019; Acuña et al., 2014; Ward et al., 2018). While underlying physical drivers of stream discharge have been extensively studied, controls on time variation in wetted channel extent remain poorly understood.

Early studies of wetted channel extent dynamics showed that higher flows at the catchment outlet were associated with higher total wetted channel lengths ( $L$, sometimes expressed as a drainage density, defined as $L$ normalized by catchment area), as revealed by plots of stream discharge at the catchment outlet ( $Q$, normalized by catchment area) as a function $L$ (e.g., Roberts 
and Archibold, 1978; Gregory and Walling, 1968; Roberts and Klingeman, 1972; Day, 1978). Biswal and Marani (2010) then formalized the notion that $L$ controls $Q$ in an investigation on the hydrograph recession. They considered hillslopes with constant specific discharge to adjacent channels, such that variations in the total discharge at the catchment outlet arise solely from changes in $L$ via its role in connecting and disconnecting contributing hillslopes.

Godsey and Kirchner (2014) proposed instead that the changes in $L$ reflect-rather than determine-changes in observed $Q$ at the catchment outlet. Based on extensive mapping of $L$ across a wide range of discharge and catchments, Godsey and Kirchner (2014) observed a power-law scaling between $L$ and $Q\left(L=\alpha Q^{\beta}\right)$. For small values of $\beta, L$ remains fairly constant with changes in $Q$, whereas for large values of $\beta, L$ changes dramatically with changes in $Q$. Across diverse catchments, small values of $\beta$ (ranging from 0.2-0.4) are typical (e.g. Godsey and Kirchner, 2014; Shaw, 2016), indicating that reductions in $Q$ are primarily driven by declines in hillslope discharge, contradicting the constant hillslope discharge proposal of Biswal and Marani (2010) in which $\beta=1$. Godsey and Kirchner (2014) pointed out that channels should be wetted if the supply of water from the upslope contributing area, $A$, exceeds the capacity of the channel to convey that supply in the subsurface, $Q_{s u b, c}$, which is locally a function of the transmissivity, $T$, of the hyporheic zone and channel slope, $S$. Prancevic and Kirchner (2019) formalized this principle to quantitatively predict $\beta$ using a set of contributing-area scaling relationships that describe how flowpath convergence (and therefore the extent of wetted channel for a given channel initiation contributing area), channel slope, and hyporheic transmissivity vary systematically throughout the channel network. These relationships, which we refer to as network hydraulic scaling (right side of Figure 1), capture spatial gradients in flow accumulating variables and the subsurface flow capacity of channels, which ultimately determine $\beta$.

The power-law relationship $L(Q)$ can be used to map a given value of $Q$ at the catchment outlet to a particular value of $L$. While $\beta$ may shift through time, for example due to sediment transport that alters hydraulic conductivity within the hyporheic zone, it is likely a relatively static landscape feature over longer timescales. The temporal variability in $L$ therefore arises from a separate driver: variability in catchment discharge, $Q$. Thus, while $\beta$ explains how $L$ varies with $Q$, it cannot fully explain the origins or magnitude of time variation in wetted channel extent. For example, variability in the length of the wetted stream channel network could remain low through time even if $\beta$ were high, as long as the flow regime exhibited minimal variation about its mean value.

Temporal variability in $L$ has been considered using flow duration curves combined with $L(Q)$ (e.g. Jensen et al., 2017), and time series plots of $L$ have appeared in the literature, either as individual point observations (e.g. Durighetto et al., 2020; Day et al., 1987; Blyth and Rodda, 1973), or via extrapolation by fitting a functional form between $L$ and $Q$ (e.g. Zimmer and McGlynn, 2017). Datry et al. (2007) summarized time variation in $L$ for two small catchments using the coefficient of variation $\left(C V_{L}\right)$, equal to the standard deviation of $L$ divided by its mean. Botter and Durighetto (2020) explored how the persistency and spatial distribution of nodes within the channel network impact the stream length duration curve using a stochastic model; their framework allows for estimating average persistency and variation of a network where spatially explicit data are available. However, a framework unifying the role of $\beta$ and $Q$ as drivers of variability in $L$ is lacking. Discerning the relative importance of these two drivers of wetted channel network stability would enable process-based predictions of the variability of $L$ due to, for example, a shift in precipitation regime. This understanding is particularly relevant for ecological 
applications, since hydrologic variability over time is a principal driver of ecosystem processes (Datry et al., 2007). Linkages have been described between flow variability and food chain length (Sabo et al., 2010), life history trade-offs (Lytle and Poff, 2004), community diversity and structure (Clarke et al., 2010), and imperiled species survival (Ward et al., 2015), suggesting that improved mechanistic understanding of surface flow intermittency can offer insight into the drivers and conditions that control how ecological variables might respond to environmental change. By decoupling the climatic and landscape influences on wetted channel variability, headwater stream networks can be classified according to their hydrologic stability, and in turn, long-term ecological stability.

Here, we present a conceptual, quantitative framework that reveals how the flow regime and network hydraulic scaling collectively govern variability in wetted channel extent, shown graphically in Figure 1. The flow duration curve, or equivalently the probability distribution of flows, encapsulates the catchment flow regime, whose variability can be succinctly summarized by the coefficient of variation (Botter et al., 2013). Our framework enables attribution of variability in the extent of the wetted channel network to network hydraulic scaling $(\beta)$ and variability in discharge $\left(C V_{Q}\right)$. We compile the globally available datasets of sites for which both flow regimes (i.e., hydrographs) and network hydraulic scaling values (i.e., $\beta$ ) exist and place them within our framework. Our results reveal that an increase in flow regime variability, which is likely to occur with projected increases in rainfall volatility and extremes (e.g. Swain et al., 2018), will result in an even greater increase in the relative variability of headwater wetted channel extents. We also use publicly available USGS hydrography data to calculate the extent of perennial and intermittent channels, as portrayed by mapped 'blue lines', within the study watersheds. Such regional streamline delineations are used extensively to direct conservation and management efforts, but it is unclear to what degree they accurately represent the active wetted channel. Results suggest that hydrographic datasets show stream network extents that are much smaller than the typical extent of wetted channels, and overlook the magnitude of temporal variation one might infer from mapped perennial and intermittent channels.

\section{Methods}

\subsection{Data acquisition}

We compiled a globally comprehensive database composed of 14 sites where wetted channel length survey data and corresponding stream hydrographs are available (see Table 1). Prancevic and Kirchner (2019) recently collected available wetted channel surveys. We sought additional sources and identified sites where streamflow timeseries are also accessible. Some sites (marked by a dagger in Table 1) did not have streamflow timeseries, but hydrographs were available by proxy from either nearby watersheds (Pioneer) or a larger watershed of which the study watershed was a subcatchment (Upper Studibach, Yellow Barn). In the former case, the regression calculated by Whiting and Godsey (2016b) was used to infer Pioneer Creek discharge, and in the latter case, discharge from proxy watersheds normalized by area was assumed representative of the study catchment.

Streamflow statistics were calculated from flow timeseries, and additional watershed characteristics were collected from the original publications and distributed sources. Climate type was reported in the data set using the Köppen Climate Classification (Köppen, 1900; Köppen and Geiger, 1930; Stern et al., 2000), as classified by Chen and Chen (2013). For this study, we 


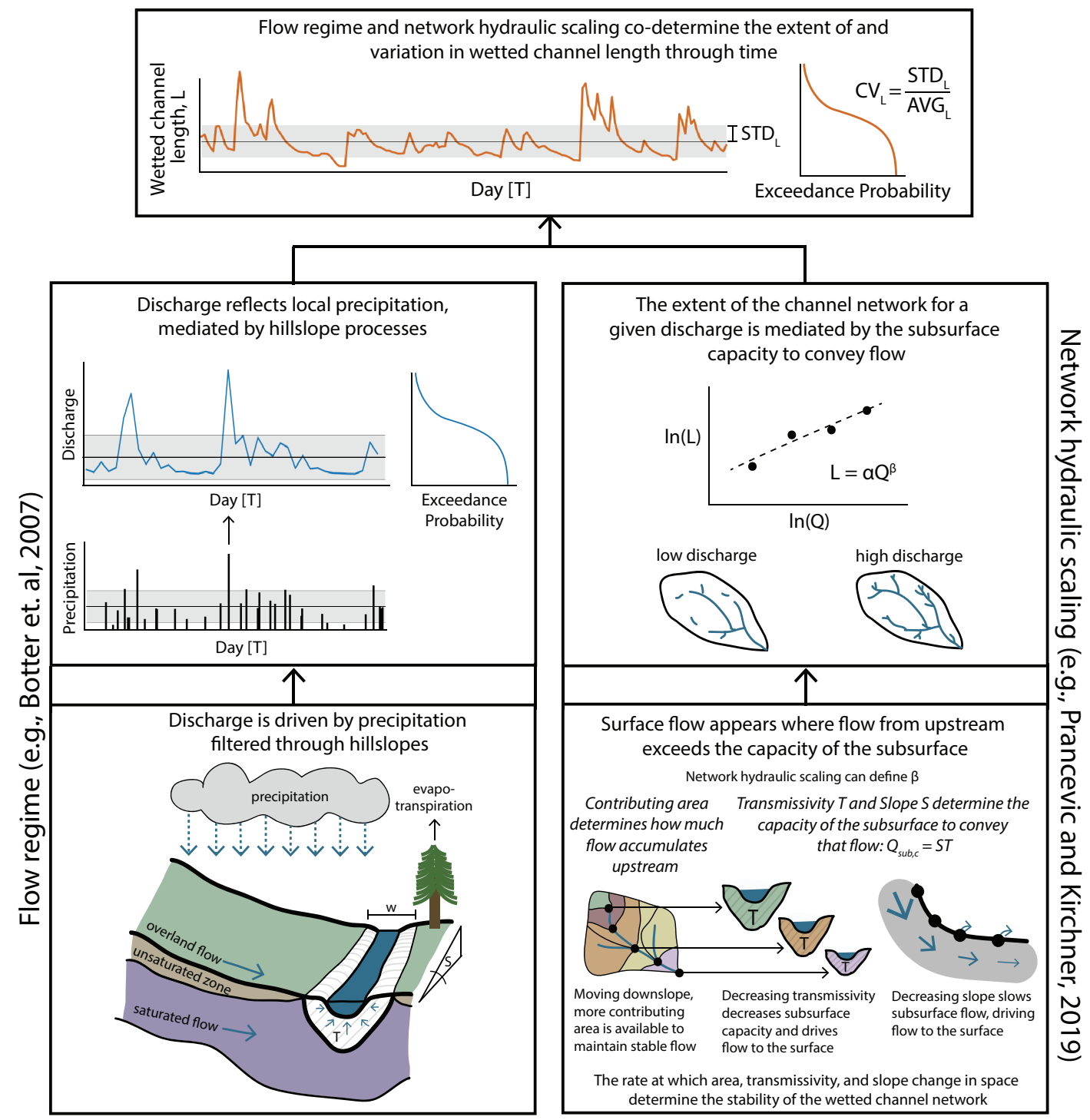

Figure 1. Conceptual figure describing the impact of flow regime (left) and network hydraulic scaling (right) on the variation in wetted channel extent $L$ (top). Hillslope runoff generation processes 'filter' precipitation events leading to time variation in discharge (left), which is delivered to the channel network. The area-dependent scaling of discharge determines the magnitude of flow delivered to the channel at any point in the stream network, and transmissivity and slope determine the capacity of the channel subsurface to convey that flow (bottom right). Where discharge exceeds this subsurface capacity, surface flow emerges, resulting in a wetted channel. The relationship between flow and wetted channel length at the catchment mouth is observed to exhibit power law scaling: $L=\alpha Q^{\beta}$ (center right). The timeseries of $Q$ and the power law relationship between $Q$ and $L$ result in a timeseries of $L$ (top) and its associated relative variability, $C V_{L}$.

simplified the classification to Mediterranean (Csa or Csb), Humid subtropical/oceanic (Cfa or Cfb), Humid continental (Dfb), and Mediterranean-influenced continental (Dsb). While $\beta$ was nearly always reported (except Zimmer and McGlynn, 2018), $\alpha$ 


\begin{tabular}{|c|c|c|c|c|c|c|c|c|c|}
\hline Catchment & Location $\left({ }^{\circ}\right)$ & Climate & Area $\left(\mathrm{km}^{2}\right)$ & $L(\mathrm{~km})$ & $Q$ (mm/day) & $\alpha$ & $\beta$ & $C V_{L}$ & $C V_{Q}$ \\
\hline Bull Creek $^{1}$ & $36.97,-119.06$ & Csa & 3.58 & $2.82 \pm 0.746$ & $1.79 \pm 3.52^{9}$ & $2.95 \pm 0.0789$ & $0.187 \pm 0.0195$ & 0.265 & 1.97 \\
\hline Caspar Creek $^{1}$ & $39.34,-123.73$ & Csb & 8.48 & $0.980 \pm 0.606$ & $1.36 \pm 4.32^{10}$ & $1.27 \pm 0.0866$ & $0.313 \pm 0.0372$ & 0.271 & 2.31 \\
\hline Duke $^{3}$ & $36.04,-79.08$ & Cfa & 0.033 & $2.15 \pm 1.80$ & $1.18 \pm 5.35^{12}$ & $3.79 \pm 0.182$ & $0.178 \pm 0.0152$ & 0.589 & 4.18 \\
\hline Elder Creek ${ }^{4}$ & $39.73,-123.64$ & $\mathrm{Csb}$ & 16.83 & $3.49 \pm 1.12$ & $3.58 \pm 8.22^{13}$ & $3.37 \pm 0.368$ & $0.185 \pm 0.0315$ & 0.321 & 2.29 \\
\hline Hubbard $42^{2}$ & $43.96,-71.72$ & $\mathrm{Dfb}$ & 0.424 & $5.63 \pm 1.84$ & $2.65 \pm 6.02^{15}$ & $5.58 \pm 0.185$ & $0.199 \pm 0.0256$ & 0.349 & 2.30 \\
\hline Pioneer Creek ${ }^{5, \dagger}$ & $45.066,-114.842$ & $\mathrm{Dfb}$ & 15.8 & $0.620 \pm 0.108$ & $0.277 \pm 0.208^{16}$ & $0.832 \pm 0.0133$ & $0.198 \pm 0.0288$ & 0.174 & 0.751 \\
\hline Providence Creek $^{1}$ & $37.06,-119.21$ & Csb & 4.01 & $1.43 \pm 0.756$ & $0.935 \pm 1.70^{17}$ & $1.79 \pm 0.113$ & $0.388 \pm 0.0639$ & 0.527 & 1.82 \\
\hline River Ray ${ }^{6}$ & $51.88,-1.01$ & $\mathrm{Cfb}$ & 18.8 & $1.48 \pm 0.813$ & $0.441 \pm 1.26^{18}$ & $2.40 \pm 0.0935$ & $0.149 \pm 0.0156$ & 0.555 & 2.84 \\
\hline
\end{tabular}

Table 1. Watershed Characteristics: Metadata for all sites included in this study. Climate zone was indicated based on the Köppen Climate Classification. $L$ and $Q$ are given as the mean value \pm the standard deviation. $\alpha$ and $\beta$ are reported with 1 standard deviation of uncertainty. Sites marked with a dagger $(\dagger)$ used a nearby watershed or a larger catchment as a proxy for hydrograph data. Data source for each site was marked next to the catchment name: [1] Godsey and Kirchner (2014), [2] Jensen et al. (2017), [3] Zimmer and McGlynn (2018), [4] Lovill et al. (2018), [5] Whiting and Godsey (2016a), [6] Blyth and Rodda (1973), [7] van Meerveld et al. (2019), [8] Shaw (2016). Data sources for hydrographs are marked: [9] Hunsaker (2019a), [10] US Forest Service (1998a) and US Forest Service (1998b), [11] Miniat et al. (2016), [12] Zimmer (2017) , [13] U.S. Geological Survey (h), [14] Edwards and Wood (2011), [15] USDA Forest Service, Northern Research Station (2020), [16] U.S. Geological Survey (f), U.S. Geological Survey (a), U.S. Geological Survey (b), U.S. Geological Survey (c) and U.S. Geological Survey (e), [17] Hunsaker (2019b), [18] UK Centre for Ecology and Hydrology (2020), [19] U.S. Geological Survey (d), [20] Stähli (2018), [21] U.S. Geological Survey (g).

was not generally reported, so we used DataThief III (https://datathief.org/) to digitize $L$ - $Q$ data from the original scatterplots to calculate $\alpha$ values and associated uncertainty, as well as to confirm reported values of $\beta$. Since total wetted channel length was the most commonly reported metric from surveys, we reported statistics and measures of total wetted channel extent only, rather than continuous wetted channel extent. The full compilation of data, including metadata and standardized streamflow timeseries are available in the data supplement (will be available on HydroShare at time of publication).

\subsection{Watershed Characteristics}

Climate grouping in this study used the Köppen classification system (Defrance et al., 2020). All study sites were either in temperate (zone C) or continental (zone D) zones; polar, monsoonal, tropical, and dry climates were not represented in the available datasets. Within the temperate and continental groups, a variety of seasonal precipitation regimes were present. Watersheds in the temperate group (zone C) included: (i) Mediterranean climates (Csa and Csb), located along the west coast of North America, which experience precipitation maximum out of phase with maximum temperatures; and (ii) humid subtrop- 
ical/oceanic climates (Cfa and $\mathrm{Cfb}$ ), located along the east coast of North America and in parts of Europe, which have fairly consistent precipitation throughout the year. Watersheds in the continental group (zone D) included: (i) humid continental climates (Dfb), located along the east coast of North America, which receive ample precipitation which is distributed across the year; and (ii) Mediterranean-influenced continental climates (Dsb), located on the west coast of North America, which have colder winters than Mediterranean climates but with rainfall still temporally out of phase with the warm season.

The soil and bedrock characteristics of the studied sites varied significantly, ranging from well- to poorly draining soils and single geologic units (Day, 1983) to complex multi-unit basements consisting of bedrock of marine origin, moraine, sandstone, and volcanic material (Durighetto et al., 2020). The catchment areas of the studied sites also ranged across 3 orders of magnitude, as shown in Table 1. Detailed soil, bedrock, and slope data are available in the data supplement (posted on HydroShare at time of publication).

\subsection{Empirical determinations of the variability in streamflow and network extent}

With the full set of available hydrographs and wetted channel surveys, we extrapolated values of $L$ for the full available hydrograph using the relationship $L=\alpha Q^{\beta}$. This procedure resulted in a timeseries of $L$ equivalent in length to the period of record of discharge. The relative variability of streamflow and network extent, described by their coefficients of variation $C V_{Q}$ and $C V_{L}$, can be calculated directly from the standard deviation and mean of the respective time series. Uncertainties in the timeseries of $L$ and its coefficient of variation were calculated using Gaussian error propagation from the uncertainties reported on $\alpha$ and $\beta$, which are depicted throughout the figures. Where not visible, the error bars were either not relevant (since neither $\beta$ nor $\alpha$ was required for the plot) or smaller than the scatter plot points. We present timeseries of $Q$ and $L$ of representative years for each site, as well as exceedance probability plots for the entire timeseries of record. The exceedance probability of $L$ is equivalent to one minus the stream length duration curve recently described by Botter and Durighetto (2020), although that study specifically focuses on flowing rather than wetted streams.

\subsection{Analytical method for determining relative variability in wetted channel length and its sensitivity to a shift in streamflow variability}

Assuming a power law relationship between $L$ and $Q$, relative variability of $L$ (that is, its coefficient of variation, $C V_{L}=$ $\left.\sigma_{L} / \mu_{L}\right)$ can be defined as a function of the flow regime and the network hydraulic scaling terms:

$C V_{L}=\frac{\sigma_{L}}{\mu_{L}}=\frac{\sqrt{\mathbb{E}\left[L^{2}\right]-\mathbb{E}[L]^{2}}}{\mathbb{E}[L]}=\frac{\sqrt{\int_{0}^{\infty} \alpha^{2} Q^{2 \beta} \cdot p d f(Q) d Q-\left(\int_{0}^{\infty} \alpha Q^{\beta} \cdot p d f(Q) d Q\right)^{2}}}{\int_{0}^{\infty} \alpha Q^{\beta} \cdot p d f(Q) d Q}$,

where $\sigma_{L}$ and $\mu_{L}$ are the standard deviation and mean of $L, p d f(Q)$ is the probability distribution function of streamflow, and $\mathbb{E}[\cdot]$ represents the expectation (mean) of the random variable. Many hydrological models and empirical studies of hy- 
drographs describe the probability distribution of discharge as a two-parameter gamma distribution (e.g. Botter et al., 2007; Muneepeerakul et al., 2010; Deal et al., 2018), in which case $C V_{L}$ was obtained as a function of $\beta$ and $C V_{Q}$ :

$C V_{L}=\frac{\sqrt{\Gamma\left(\frac{1}{C V_{Q}{ }^{2}}\right) \Gamma\left(2 \beta+\frac{1}{C V_{Q}{ }^{2}}\right)-\Gamma\left(\beta+\frac{1}{C V_{Q}^{2}}\right)^{2}}}{\Gamma\left(\beta+\frac{1}{C V_{Q}{ }^{2}}\right)}$.

Here, $\Gamma(\cdot)$ is the gamma function (Abramowitz and Stegun, 1948). To directly explore the sensitivity of $C V_{L}$ with respect to changes in $C V_{Q}$, we calculated the elasticity of $C V_{L}$ with respect to $C V_{Q}$ for the case of gamma-distributed $Q$ :

$$
\begin{aligned}
E\left(C V_{L}\left(C V_{Q}\right)\right)= & \frac{C V_{Q}}{C V_{L}} \frac{\partial C V_{L}}{\partial C V_{Q}} \approx \frac{\% \Delta C V_{L}}{\% \Delta C V_{Q}} \\
= & \frac{\Gamma\left(2 \beta+\frac{1}{C V_{Q}^{2}}\right) \Gamma\left(\frac{1}{C V_{Q}^{2}}\right)\left(\psi\left(\beta+\frac{1}{C V_{Q}^{2}}\right)-\psi\left(2 \beta+\frac{1}{C V_{Q}^{2}}\right)-\psi\left(\frac{1}{C V_{Q}^{2}}\right)\right)}{C V_{Q}^{2}\left(\Gamma\left(2 \beta+\frac{1}{C V_{Q}^{2}}\right) \Gamma\left(\frac{1}{C V_{Q}^{2}}\right)-\Gamma\left(\beta+\frac{1}{C V_{Q}^{2}}\right)^{2}\right)}
\end{aligned}
$$

where $\psi(x)$ is the $0^{\text {th }}$ order polygamma function (Abramowitz and Stegun, 1948); integration and simplification of Equations 2 and 3 were performed in the mathematical programming language Mathematica. Elasticity can be interpreted as the percent change in $C V_{L}$ relative to a percent change in $C V_{Q}$ for a particular value of $C V_{Q}$ (e.g. Harman et al., 2011). When elasticity is 1 , then $C V_{L}$ changes to the same degree (proportionally) as $C V_{Q}$. Values larger than 1 indicate that $C V_{L}$ has heightened sensitivity to changes in $C V_{Q}$, and values smaller than 1 indicate that $C V_{L}$ has diminished sensitivity to changes in $C V_{Q}$.

Equations 2 and 3 enabled an exploration of the sensitivity of $C V_{L}$ to shifts in $C V_{Q}$ for particular values of $\beta$. If discharge is gamma distributed, and if a power-law relationship is used to obtain $L$ from $Q$, then Equation 2 should exactly match the empirically calculated $C V_{L}$. Comparison between empirical and theoretical $C V_{L}$ therefore assesses the degree to which discharge is gamma distributed.

While other functional forms of $p d f(Q)$ may be used to obtain an expression for $C V_{L}$, an advantage of using a gamma probability distribution for discharge is that existing model frameworks enable interpretation of $C V_{Q}$ in terms of physical landscape and climate parameters. Botter et al. (2007) demonstrate that gamma-distributed discharge may arise from a simple, process-oriented description of rainfall-runoff processes within a catchment. In this way, variability in the flow regime may be used to directly explore the dependence of $C V_{L}$ on the climatic and hydrogeologic attributes of a watershed.

For a more general description of $C V_{L}$ that does not rely on the assumption that discharge is gamma distributed, we also derived a formula using Taylor expansions of the mean and standard deviation of $L$; however, error in the truncated Taylor series proved too large to capture $C V_{L}$ for values of $C V_{Q}$ greater than approximately 2.

Costigan et al. (2016) introduced a framework underscoring the importance of meterologic, geologic, and land use factors in influencing non-perennial stream dynamics. Our model incorporated each aspect of the framework, with meteorologic and climatic information included in in $C V_{Q}$, and geologic aspects of the basin included in $\beta$. Land use was implicitly included in both $C V_{Q}$ and $\beta$. Land use changes can affect the way hillslopes filter precipitation with dramatic impacts on the hydrograph 
and along-channel flow dynamics. For example, changes in evapotranspiration with changing plant communities, an increase in impermeable surface cover, or removal of in-channel wood can affect the runoff frequency, the hillslope recession constant, and the capacity of the channel to convey flow in a way that causes shifts in $C V_{Q}$ and $\beta$.

\subsection{Assessing the ability of the gamma distribution to describe the flow regime}

Since our analysis is predicated on the assumption that discharge is gamma distributed, we explored the extent to which this assumption held for each site. For this analysis, hydrographs were analyzed in their entirety and also separated by northern hemisphere season (i.e. winter is December-February, spring is March-May, summer is June-August, and fall is SeptemberNovember) since a gamma fit may be more appropriate on a seasonal basis in some climates. For each site and each season, we fit a gamma distribution to the discharge timeseries using Maximum Likelihood Estimation (MLE). We use the $R^{2}$ between (i) the relationship between empirical and fitted quantiles of $Q$ and (ii) a 1:1 line. This is mathematically equivalent to the NashSutcliffe model efficiency coefficient (NSE) of flow quantiles, which we will use to refer to this metric throughout the text. We use a threshold of 0.65 , which has identified as a threshold for acceptable fit using the NSE (Ritter and Muñoz-Carpena, 2013) and fits well within the fit categories used by Müller et al. (2014) and Castellarin et al. (2004) for NSE of flow quantiles ([0.75-1]: good, [0.5- 0.75]: fair, [-inf,0.5]: poor). Since full hydrographs were generally fit well by a gamma distribution in this study, results that employ Equations 2 and 3 are only shown for full timeseries for simplicity.

\subsection{USGS blue line comparison}

We determined the blue stream line drainage density from GeoPDFs of the most recently published 7.5' USGS topographic maps for the study watersheds in the United States. We collected this data to compare the topographic map definitions of perennial stream (solid blue lines) and intermittent stream (dashed blue lines) to the wetted channel extents determined from the $L(Q)$ relationships. The USGS defines a perennial stream as a stream that normally has water at all times except during rare droughts. The USGS defines an intermittent stream as one that flows only when it receives water from a spring or from rainfall but flows more than an ephemeral stream, which only flows in response to precipitation. Busch et al. (2020) recommend using the term 'non-perennial' for streams that have interruptions in surface expression, so we use that term throughout in general, but intermittent is used specifically according to the USGS definition.

\section{Results}

\subsection{Data synthesis}

Figure 2 shows timeseries of $Q$ (as discharge per catchment area) and $L$ (as total wetted channel length per catchment area) for a representative year for each site where $Q$, and $\alpha$ and $\beta$ values, are available. All data are plotted on the same vertical axes for comparison, with logarithmic scaling for $Q$ and linear scaling for $L$. There was a large range in hydrograph behavior among the sites, from relatively smooth and seasonal hydrographs like Sagehen Creek to highly variable flashy hydrographs like Duke. 

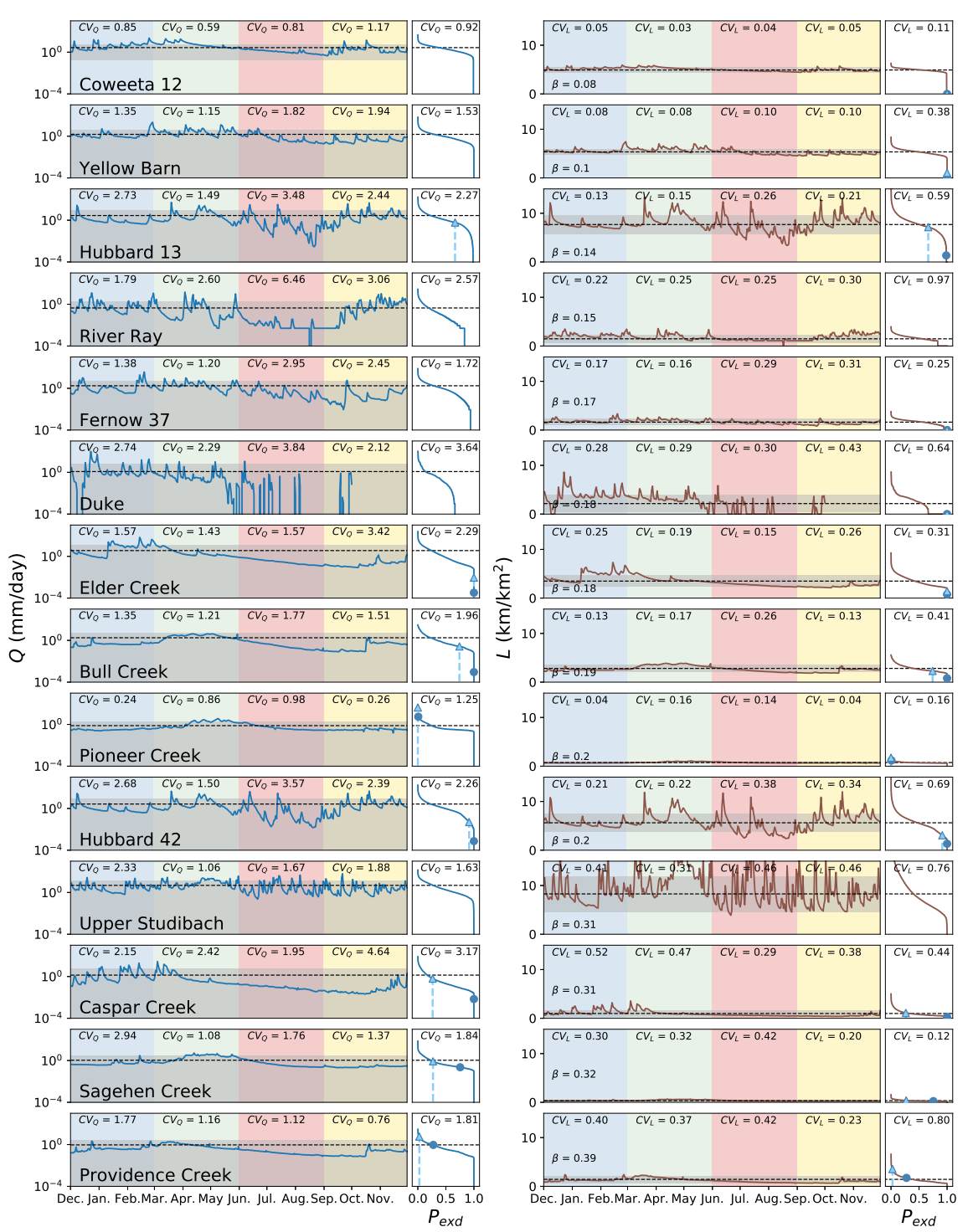

Figure 2. Representative annual hydrographs (left) and corresponding wetted channel length $L$ timeseries (right) given $L=\alpha Q^{\beta}$ for all sites included in this study, listed in order of increasing $\beta$. Data are plotted for one representative year, with shading marking northern hemisphere seasons: blue (DJF), green (MAM), red (JJA), and yellow (SON). Dashed black lines indicate the mean for the full timeseries, and the shaded gray region covers the interval of one standard deviation around the mean (note log scale for hydrographs). $C V_{Q}$ and $C V_{L}$ are reported by season in each colored region and for the total timeseries in the flow-duration/length-plots. Marked points indicate USGS 7.5' perennial channel extent/associated discharge (dark blue) and combined perennial and ephemeral channel extent/associated discharge (light blue). All $C V$ values are calculated over all years of available data. Site name is found on the discharge timeseries, and $\beta$ is marked on the $L$ timeseries. Exceedance probabilities $P_{\text {exd }}$ are shown to the right of each timeseries. 
There is a corresponding large range in observed $C V_{Q}$ values calculated for the entire timeseries among these sites, from a minimum of 0.92 for Coweeta 12 to a maximum of 3.65 for Duke, with the most common $C V_{Q}$ around 2. Values of $C V_{Q}$ were also calculated within seasons and in most cases tend to bracket values of annual $C V_{Q}$. Relative variability in $Q$ necessarily exceeds relative variability in $L$ because $\beta$ is less than one, which dampens the impact of variation in $Q$ on the timeseries of $L$. Moving down Figure 2, $\beta$ increases, and $C V_{L}$ generally increases with increasing $\beta$. It is important when considering the mean stream conditions to note that, as $\beta$ results in a nonlinear transformation from the timeseries of $Q$ to that of $L$, the exceedence probability of the mean flow $\mu_{Q}(15-37 \%)$ is distinct from that of the mean wetted channel network extent $\mu_{L}(32-53 \%)$. In all cases, $\mu_{L}$ occurs at a flow rate lower than $\mu_{Q}$.

\subsection{How does variability in $Q$ impact variability in $L$ for different values of $\beta$ ?}

Equation 2 was plotted in the contour plot of Figure 3(a), which shows that where the network hydraulic scaling term $\beta$ is small, $C V_{L}$ is also generally small. As $\beta$ increases, much larger values of $C V_{L}$ are possible. Scatter points in Figure 3 (a) show the relationship between $\beta$ and the empirically calculated $C V_{Q}$ from the entire timeseries for all sites in the dataset acquired for this study. The majority of our sites have $0.2 \leq \beta \leq 0.4$ and $1.5 \leq C V_{Q} \leq 2.5$. In this part of the space, values of $C V_{L}$ are generally below 1 .

Figure 3 (a) enables prediction of how network hydraulic scaling $(\beta)$ and a given flow regime (defined by its relative variability $C V_{Q}$ ) determine $C V_{L}$. While $\beta$ is a relatively static landscape property, $C V_{Q}$ may change over time due to, for instance, changing climate or patterns of anthropogenic surface water use. Given a shift in $C V_{Q}$, what is the impact on $C V_{L}$ ? Shifting points up or down vertically along the $C V_{Q}$ axis in Figure 3 (a) results in a new value of $C V_{L}$. As $C V_{Q}$ increases, $C V_{L}$ increases. Figure 3 (b) more clearly reveals how change in $C V_{Q}$ impacts $C V_{L}$ using elasticity. Elasticity can be interpreted as the fractional change in $C V_{L}$ relative to a small fractional change in $C V_{Q}$ for a given value of $C V_{Q}$ and $\beta$. If elasticity is 1 , then $C V_{L}$ and $C V_{Q}$ change at the same relative rate. As elasticity increases, changes in $C V_{L}$ will be proportionally larger than changes in $C V_{Q}$. As elasticity decreases, changes in $C V_{L}$ will be proportionally smaller than changes in $C V_{Q}$. Elasticity is at least 1 everywhere throughout the space (i.e, when $0<\beta \leq 1$ ). While elasticity is nearly 1 for $\beta>0.4$, when $\beta$ is smaller, changes in $C V_{L}$ have heightened sensitivity to changes in $C V_{Q}$ (elasticity $>1$ ). Elasticity describes the 'instantaneous' change in $C V_{L}$ for a change in $C V_{Q}$; however, similar relative changes would be exhibited with larger changes in $C V_{Q}$ because vertical shifts in $C V_{Q}$ do not cause points to cross many contour lines of elasticity. For example, as shown in Figure 3 (c), if $C V_{Q}$ doubles, then all of the points lying in regions of darker green in Figure 3 (b) will experience more than a doubling in $C V_{L}$ (average 2.30 for all sites). A halving of $C V_{Q}$ similarly results in more than a halving in $C V_{L}$ for many sites in this study (average factor less than half, 0.43). Surprisingly, the region most sensitive to changes in $C V_{Q}$ aligns with the region where the majority of studied sites fall.

\subsection{How applicable is the theoretical model to actual catchments?}

Sites in this study generally exhibit gamma-distributed flow, so the theoretical model presented should accurately capture the relationships between $C V_{L}, C V_{Q}$, and $\beta$. Figure 4 (a) shows the NSE ( $R^{2}$ between empirical and fitted quantiles of $Q$ and a 
(a)

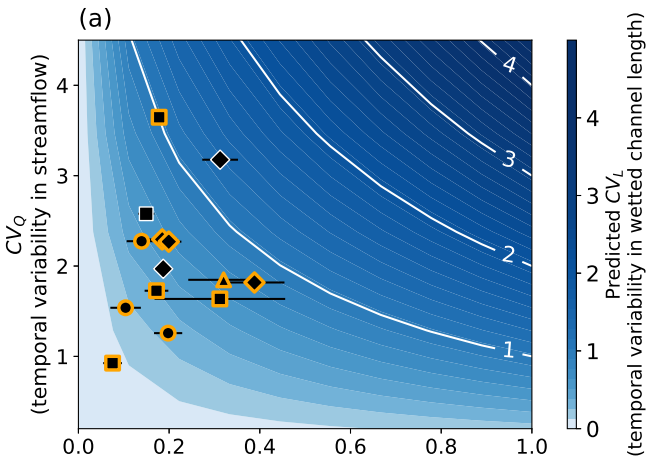

(b)
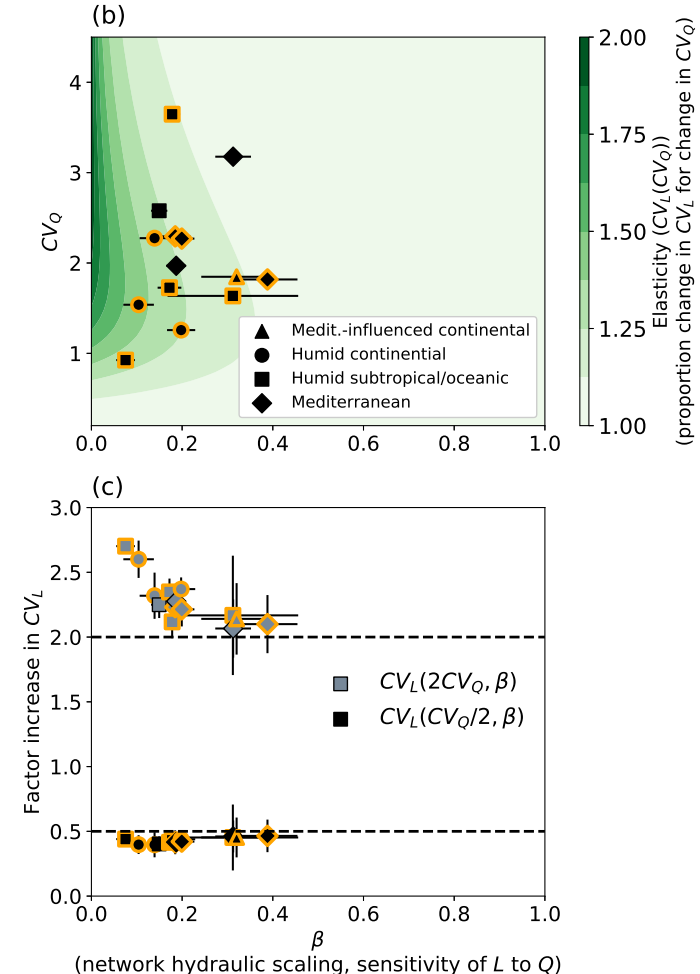

Figure 3. (a) Relative variability in flow regime $\left(C V_{Q}\right)$ and network hydraulic scaling $(\beta)$ govern relative variability in wetted channel extent $\left(C V_{L}\right)$ under simplifying model assumptions (i.e., gamma-distributed $\left.Q\right)$. Points show flow regime and and network hydraulic scaling of actual catchments, with symbol shape denoting climate zone (legend in(b)). (b) There is exaggerated sensitivity of $C V_{L}$ to changes in $C V_{Q}$ for small values of $\beta$ and moderate values of $C V_{Q}$, where nearly all study sites lie. (c) For either a doubling (grey) or halving (black) of $C V_{Q}$, the fractional change in $C V_{L}$ is more extreme; points lie beyond the dashed lines. Gold outlines in all panels indicate that flow is fit well by a gamma distribution $(N S E>0.65)$.

1:1 line) and \% error in $C V_{Q}$ when estimated using a gamma distribution. The shaded region is NSE $>0.65$, the threshold for acceptable fit. The majority of the sites fall within this region. In Figure 4 (b), the relationship between $C V_{L}$ empirical and 
$C V_{L}$ predicted using Equation 2 is shown for each site. The points fit well by a gamma distribution (NSE $>0.65$, outlined in orange) lie close to the dotted 1:1 line, confirming that the model is appropriate in describing $C V_{L}$ for the full timeseries. For a discussion of model fit on a seasonal basis, see Appendix Section B.
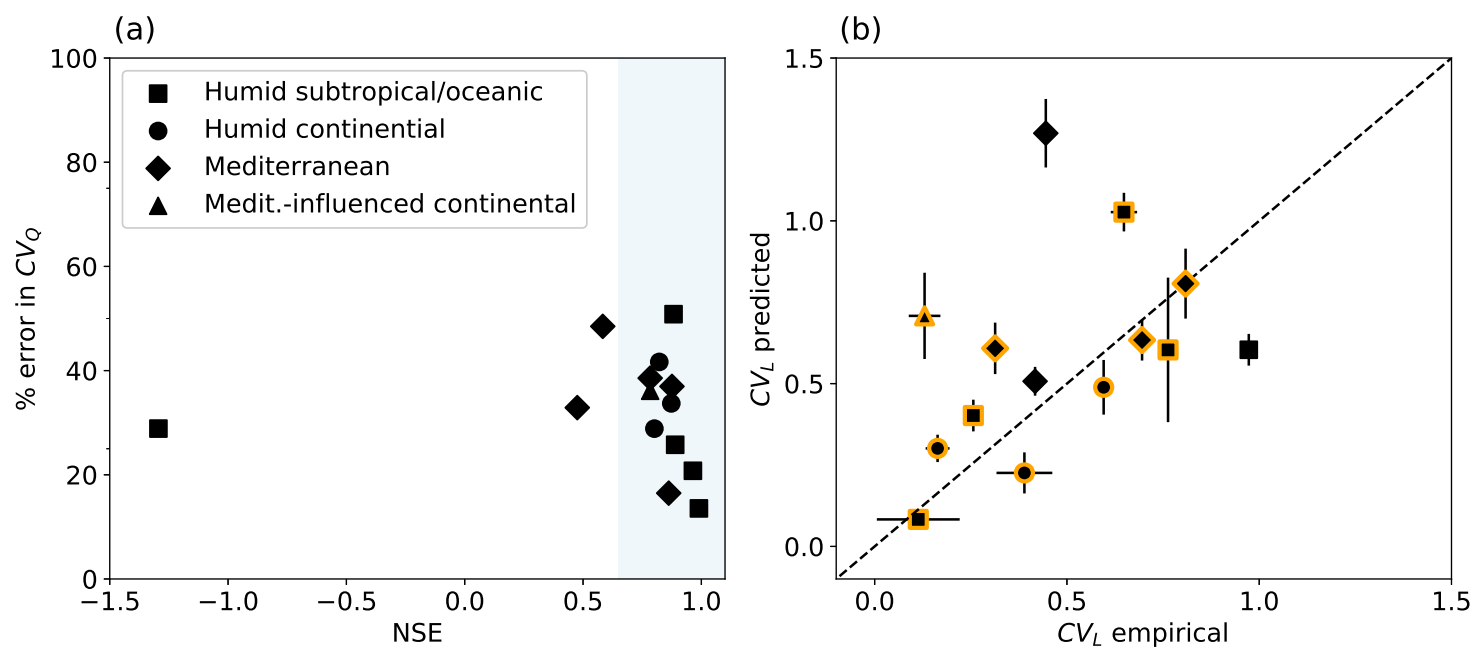

Figure 4. How well does the gamma distribution describe actual hydrographs, and how does this affect predictions of $C V_{L}$ ? (a) plots the percentage difference between model-predicted and empircally derived $C V_{Q}$ vs. the NSE goodness-of-fit criteria for gamma distribution and actual hydrograph percentiles for NSE $>0$. Shaded region indicates $N S E>0.65$. (b) Comparison between $C V_{L}$ calculated from the empirical hydrograph timeseries and the predicted value based on $C V_{Q}$ and $\beta$ (from the model in (a)). The dashed line shows one-one correspondence for reference. Error bars incorporate the uncertainty in $\alpha$ and $\beta$. Points outlined in gold meet the selection criteria for the gamma fit.

\subsection{Stream network extents in relation to USGS blue line stream mapping}

The USGS 7.5' solid blue line network does not capture the inferred wetted channel network extents in this study, plotted along the flow-duration and $L$-duration curves in Figure 2. As shown in dark blue in Figure 5 (a) the drainage density of the perennial stream network (solid blue lines on USGS maps) is systematically smaller (average factor of 1.4) than the empirically inferred wetted channel network from the $L=\alpha Q^{\beta}$ relationship at the lowest recorded flow (100\% exceedance probability). The USGS solid blue line network extents are smaller than the minimal wetted channel extents calculated from the flow regimes and network hydraulic scaling in all except three cases, with a median percent difference of $54 \%$. Furthermore, the difference between the empirically calculated wetted channel drainage density and the USGS blue line drainage density is highly inconsistent between sites, such that there is not an obvious way to infer perennial wetted channel extents from the USGS solid blue line network.

A similar relationship holds between the drainage density of the total stream network mapped by the USGS (solid and dashed blue lines) and the highest ( $0 \%$ exceedance probability) empirically inferred wetted channel network extent (Figure 5); 
the highest inferred $L$ ( $0 \%$ exceedence probability) is always greater than the USGS total network extent with a median percent difference of $78 \%$ and an average factor difference of 3.9. This is not particularly surprising, as the USGS excludes ephemeral stormflow by definition, which the flow regime would capture. However, only just over half of the total USGS network extents even exceed the lowest wetted channel network extent inferred from $L=\alpha Q^{\beta}$ (100\% exceedance probability), shown in the grey region of Figure 5 (b). Pioneer Creek is an outlier among these sites as the only site for which both USGS perennial and combined perennial and intermittent are far greater than the lengths inferred from $L=\alpha Q^{\beta}$. The individual USGS stream network extents may therefore capture some, none, or all of the dynamic variability inferred from the wetted channel mapping campaigns.

(a)

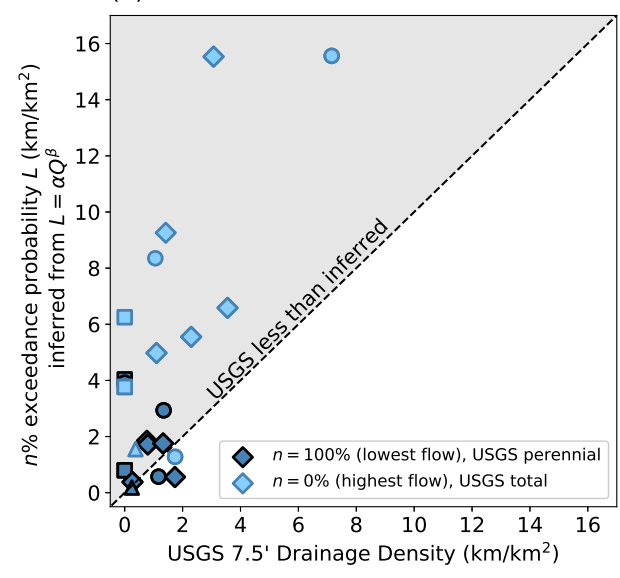

(b)

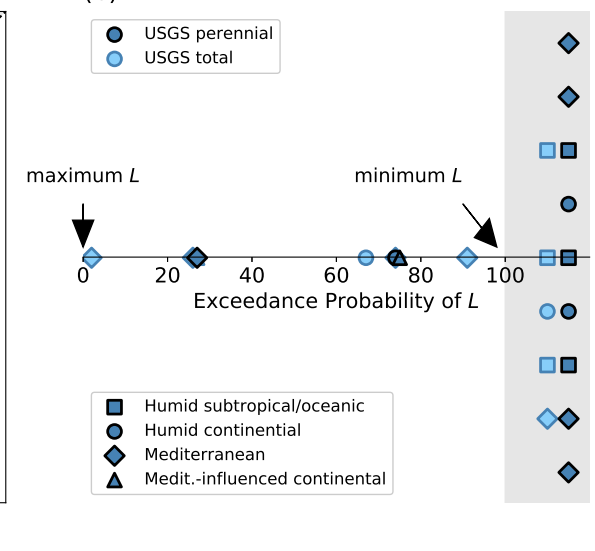

Figure 5. (a) USGS 7.5' blue line stream extent is nearly always less than both perennial and dynamic stream extents inferred from the $L(Q)$ relationship. (b) The exceedence probability for USGS 7.5' blueline channel extents is often greater than $100 \%$. Points in the grey region beyond $100 \%$ have values well below the smallest inferred $L$, and total stream lengths fall along the full spectrum of possible exceedence probabilities.

\section{Discussion}

We have formalized the joint control on the temporal variability in wetted channel extent $\left(C V_{L}\right)$ by network hydraulic scaling relationships (in the form of $\beta$, which determines how much $L$ changes for a change in $Q$, as suggested by Prancevic and Kirchner, 2019; Godsey and Kirchner, 2014) and the flow regime (described by $C V_{Q}$, e.g., Botter et al., 2007). Our approach is summarized in Figure 1. The collection of all sites with jointly available streamflow and $\beta$ values from the literature (Figure 2; Table 1) reveals that relative variability in discharge greatly exceeds (often by a factor of $>5$ ) relative variability in wetted channel extent. By assuming that flow is well-approximated by a gamma distribution, we predicted $C V_{L}$ as a function of $C V_{Q}$ and $\beta$ (Figure 3). An increase in the relative variability of streamflow $\left(C V_{Q}\right)$ results in an even greater increase in the relative variability in wetted channel extents $\left(C V_{L}\right)$. Perhaps surprisingly, this elasticity is greatest for small $\beta$. The location of sites 
from around the world within this plotting space suggests that for most places, an increase in the relative variability of discharge under a shifting climate regime will result in an even greater increase in the relative variability of wetted channel extents.

This study provides a framework for assessing the controls on $C V_{L}$ between different sites under current conditions as well as a way to predict changes in $C V_{L}$ under a shifting climate. Climate change is projected to result in more volatile precipitation regimes with more frequent extreme events in many locations globally, without necessarily changing mean precipitation totals (Swain et al., 2018; Seneviratne et al., 2012). We can understand how a change in the variability in precipitation will affect variability in the wetted channel network extent under the assumptions of a simplified stochastic hydrologic model (Botter et al., 2007), described in Section $2.4, C V_{Q}=\sqrt{k / \lambda_{Q}}$. Within this model, climate is embedded within $C V_{Q}$ via $\lambda_{Q}$. Increasing precipitation volatility with a constant or decreasing mean will result in a decrease in the frequency of rainfall events. A decrease in the frequency of rainfall events translates into a decrease in the frequency of runoff events, as the Botter et al. (2007) model indicates, so higher precipitation volatility would be expected to result in larger $C V_{Q}$. In parallel to increased precipitation volatility, rising temperatures will increase evapotranspiration demand (Kingston et al., 2009). This could increase actual evapotranspiration, resulting in vegetation withdrawing more moisture from the vadose zone and increasing the threshold amount of rainfall required to then initiate a streamflow event. This suggests that greater potential evapotranspiration could also lead to a decreased frequency of runoff events (i.e., smaller $\lambda_{Q}$ ) and therefore larger $C V_{Q}$. Thus, the projected shifts in climate could result in a significant increase in $C V_{Q}$, which our findings indicate would result in an even greater relative increase in $C V_{L}$ for headwater stream networks.

\subsection{Implications for physical and chemical streamwater dynamics}

Variability in wetted channel extent should impact variability in solute export dynamics. Wigington Jr et al. (2005) showed that nitrate concentrations scaled with stream network length in western Oregon, and Hale and Godsey (2019) showed that variability in $L$ impacts dissolved organic carbon (DOC) concentrations. Both Wigington Jr et al. (2005) and Hale and Godsey (2019) suggested that connection to source areas is the likely mechanism by which variation in $L$ regulates these solute concentrations.

The total surface area of water is important for determining chemical exchange between water and the atmosphere, including the process of $\mathrm{CO}_{2}$ evasion. This is not only important for chemical cycling but also for energy flux to the channel. Studies that have attempted to estimate the global surface area of rivers have done so by extrapolating channel areas observed at mean annual discharges (Allen and Pavelsky, 2018). Our findings suggest that the average length of headwater streams is about 20\% less than that predicted using the mean annual discharge. (Barefoot et al., 2019) found that increases in headwater stream surface area with increasing runoff were equally contributed by longitudinal and lateral expansion, so surface area of streams should scale with longitudinal extent, indicating that average river area in headwater streams may be overestimated at mean discharge.

Understanding the availability of surface water (and hyporheic zone storage, included in $\beta$ ) is critical, as it impacts several physicochemical processes, including evaporative cooling of the local atmosphere as well as in-stream temperatures. Drier conditions result in a contraction of the wetted stream area, leading to much greater daily variability in channel water temperature 
than would occur under wet conditions (since water has a greater specific heat than air). Rapidly changing water temperatures can be unsuitable or lethal for aquatic species (Beitinger et al., 2000), and swings in temperature also dictate available energy for chemical reactions in the water and chemical exchange with the atmosphere. As an increase in variability in $L$ leads to increased variability in temperature, an increase in variability, even at the same mean, could increase stress on aquatic organisms and alter stream chemistry.

\subsection{Ecological Impacts}

On longer-term timescales, the inter- and intra-annual variability of streamflow are critical components of the natural flow regime to which biota both respond and adapt (Stubbington et al., 2017). While many species are attuned to variation in discharge and wetted channel length, they rely on certain phenological conditions for survival. For example, organisms' life history strategies use as cues metrics like average timing of winter floods, spring recession, and summer low flows to initiate certain developmental stages (Lytle and Poff, 2004). Looking at the seasonal differences in $C V_{Q}$ and $C V_{L}$ (Figure 2) can provide insights into how reliable these cues are, and how these may impact phenological bottlenecks in survival.

An overarching concern for predicting the fate of aquatic ecosystems is that while hydrologic variability has been identified as a control on ecological processes, many of the current empirical relationships that are used to govern management decisions are rooted in climatic stationarity (Horne et al., 2019). These assumptions fail to incorporate a shifting baseline climate regime, with already variable regions predicted to become even more volatile. For example, in California, which experiences a highly variable Mediterranean climate, future climate is projected to have an exacerbated seasonal cycle, with rapidly alternating drought and flood periods (Swain et al., 2018). This has direct implications for the ecological dynamics within these systems, where intermittency of headwater river networks is typically the norm rather than the exception, and aquatic species rely on wetted channel reach refuges during network extraction. Our study addresses recent calls for novel strategies to adaptively manage river ecosystems, with a focus on process based models that incorporate increasing climatic variability Tonkin et al. (2019). For headwater stream networks that are expected to exhibit greater variability based on their location within the elasticity plotting space of Figure 3 (b), a shift in community composition may occur (Brooks, 2009), resulting in a new composition of species that are resistant or resilient to increased variability (Poff et al., 1996). Networks that are relatively more buffered from potential increases in streamflow variability can act as a refuge for aquatic species. These refugial networks may harbor keystone communities (Mouquet et al., 2013), and become a focus for management efforts.

\subsection{Management implications}

Correct classification of streams is essential for effective management, as perennial and non-perennial streams function differently and provide different ecosystem services. Stream classification also determines which governing body is in charge of regulation (e.g., federal or state). In the US, USGS maps are often one of the main tools used for preliminary distribution of surface water resources for both management and conservation purposes. Our results demonstrate that the USGS 7.5' blue line stream network under-represents both the perennially wetted stream extent and the dynamic wetted stream extent in nearly all US sites included in this study (excluding Pioneer Creek, which is over-represented). That is, both perennially 
and non-perennially wetted channel segments are generally either underestimated, or, in many cases, totally absent from the map. Meerveld et al. (2019) also compared surveyed stream extents to topographic maps and found similarly that topographic maps showed much smaller stream extents than they observed. If this patterns hold elsewhere, then the solid blue line USGS stream network is systematically smaller than the perennially wetted channel network and dynamically active non-perennial network across the US. Since legislative categories are based on specification of channel segments as perennial or non-perennial (Acuña et al., 2014), misidentification of stream segments will cause legislation to be applied differently than intended or not at all, where stream segments are missing from USGS maps. Additionally, since we found no systematic pattern in the underrepresentation of streams in USGS maps, legislation would be applied differently in different locations, leading to inconsistent management. This finding adds urgency to the development of adaptive large-scale wetted channel maps that incorporate the variability and likely non-stationarity exhibited by the sites in this study.

\subsection{Limitations of model and analysis}

\subsubsection{Extrapolation where mapped network extents do not cover the full range of flows}

The power law relationship between $L$ and $Q$ enables calculation of timeseries of wetted channel length from timeseries of discharge. Although this relationship has been observed to be robust in studies that span nearly the entire range of flows on record (e.g., Godsey and Kirchner, 2014; Jensen et al., 2017; Meerveld et al., 2019), some studies of wetted channel extent span highly limited ranges in flow. Lovill et al. (2018), for example, focused on dry season recession dynamics in Elder Creek, and their highest-flow survey occurred at only the 40th percentile of flow. Constructing the timeseries of $L$ from the hydrograph using the empirical relationship $L=\alpha Q^{\beta}$ therefore requires, in some cases, significant extrapolation beyond the empirically observed range of flows. The calculations of $C V_{L}$ in this study are contingent on the validity of this extrapolation, which could be validated with future mapping at targeted flow percentiles.

\subsubsection{Hystersis in relationship between wetted channel length and $Q$}

The relationship between $L$ and $Q$ may exhibit hysteresis. Blyth and Rodda (1973) suggested distinct relationships between $L$ and $Q$ by season, which was observed at one site by Godsey and Kirchner (2014) in their reanalysis of data from Gregory and Walling (1968). Distinct $\alpha$ and $\beta$ values between winter and summer surveys were observed. For some studies included in the compiled dataset, surveys were conducted in particular seasons (e.g. Lovill et al., 2018). Using the same relationship throughout the year may not be justified, and fitting a single relationship for surveys taken throughout the whole year may alter measured variability in $C V_{L}$. Hysteresis in the relationship between $Q$ and $L$ may also occur on an event basis. Bhamjee and Lindsay (2011) noted that distinct modes of expansion and contraction (e.g., upstream or downstream) could occur during wetting and drying. Roberts and Archibold (1978) and Zimmer and McGlynn (2017) found that distinct wetted channel lengths can be associated with the same value of $Q$, depending on whether the survey is done on the rising or falling limb of the hydrograph. Future improvements on the analyses presented here could incorporate time-varying relationships between $Q$ and $L$ when sufficient data become available. 
In this study, we examine and report on parameters related to the total extent of wetted channels, since this was the most commonly reported metric in the literature. Some studies also mapped and reported the continuously wetted channel network extent, which may be a more relevant metric in certain contexts. For example, the extent of continuously wetted channels likely dictates mobility and food delivery downstream for many aquatic organisms. Wetted extent is also a coarse ecological metric, standing in for relevant reach-scale variables like water depth, width, and flow rate. The flowing channel network may also be distinct from the wetted channel extent explored in this study since standing water does not count toward flowing channel length. Flowing channels may be more important for some ecological applications and are often referred to in legislation about streams. Future studies could exploit empirically determined scaling relationships between these variables and $L$ to predict their variability as well.

\subsubsection{Data is limited in geographic and temporal extent}

Headwater streams have been called aqua incognita due to their relative lack of study (Bishop et al., 2008). While ubiquitous, many headwater streams are simply absent from maps or receive little attention, despite their importance for a variety of ecological, geochemical, and geomorphological processes. Non-perennial streams can constitute the majority of the total stream length across many regions (Goodrich et al., 2018); thus, changes in variability or length of wetted stream networks have an enormous impact on total stream habitat availability and quality. These understudied reaches are also vulnerable to climate change, as suggested by the amplified impact in $C V_{L}$ of increases in $C V_{Q}$ demonstrated in this study.

As shown in the map in Appendix A, there is a strong geographic bias towards North America in the data sets available for inclusion in this study, with only 2 sites in Europe, 1 in Australia, and none in South America, Africa, or Asia. While the majority of these headwater catchments have $0.2<\beta<0.4$, the true distribution of $\beta$ globally is still unknown, given the geographic concentration and small number of surveyed dynamic stream extents. One particularly promising avenue for increasing the number of datasets exploits advances in drone-based mapping technologies that could rapidly enable repeat, high resolution mapping of wetted channel extents (e.g. Hooshyar et al., 2015).

\section{Conclusions}

We developed a conceptual model for how the flow regime and network hydraulic scaling collectively determine the extent of the wetted channel network. Using our conceptual framework, we explored empirical variability in wetted channel extent and employed a modeling framework for predicting changes in $C V_{L}$ assuming gamma-distributed streamflow. A compilation of all available data from 14 sites around the world revealed that headwater stream extents were significantly less variable than streamflow because network hydraulic scaling dampens variability in $Q$ through the relationship $L=\alpha Q^{\beta}$, where $\beta<1$ always. Although variability in $L$ is dampened, the relationship is elastic, such that for a given change in $C V_{Q}$, headwater streams will experience an even more extreme change in $C V_{L}$. Therefore, headwater stream network extents are very sensitive 
to a shift in climate toward less frequent runoff events, as projected in many places around the world. We compared the wetted channel extents determined from the $L(Q)$ relationship to USGS stream delineations, and found that published stream networks are persistently underestimated. Given its use in making legislative, management, and conservation decisions, we recommend that hydrographic datasets incorporate the variability in wetted channel extent.

\section{Data availability}

All code and data will be available for download from HydroShare at time of publication.

Competing interests. The authors declare that we have no competing interests.

Acknowledgements. Funding for this work was provided by Simon Fraser University and a Natural Sciences and Engineering Research Council of Canada (NSERC) Undergraduate Student Research Award (USRA) to Leclerc and Hahm. We thank Margaret Zimmer for sharing

\section{Appendix A: Global site map}

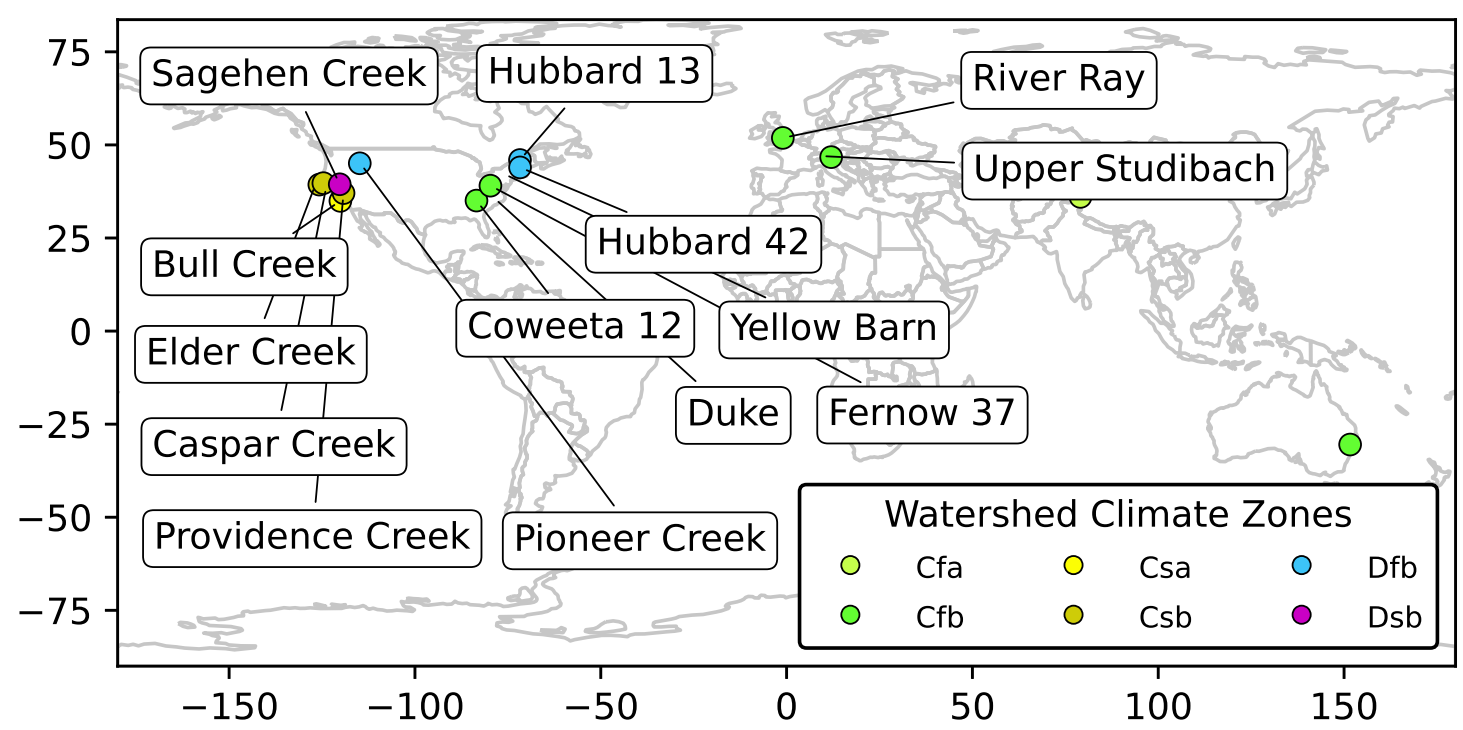

Figure A1. Global map showing the geographic location of each site included in this study. 
Figure A1 maps the locations of all sites included in this study. The vast majority of site are in North America, particularly along the eastern and western sides of the United States of America. Only two sites are in Europe and one in Australia, with no sites in South America, Africa, or Asia. Despite the geographic limitations, the sites span a large range of climate types and topographies. More wetted channel surveys will be required to extend these results to a truly globally-encompassing analysis.

\section{Appendix B: Seasonal gamma fit}

For all seasons and sites included in this study, the majority of streamflow timeseries are fit well by a gamma distribution (Figure B1). As shown in Figure B1 (a), NSE $>0.65$ (the limit for acceptable gamma fit), covers most of the points, and as NSE increases, \% error in $C V_{Q}$ generally decreases, indicating that NSE is an appropriate metric of fit over the full set of data. In general, all full timeseries are fit similarly well to seasonal timeseries by a gamma distribution (Figure B1 (b) and (c)), although spring timeseries generally have the highest NSE and lowest \% error in $C V_{Q}$. For some individual sites, a seasonal gamma fit to some seasons is acceptable whereas the fit for the full timeseries is not. These sites have significant seasonal variability that makes a gamma distribution unsuitable for the full hydrograph.
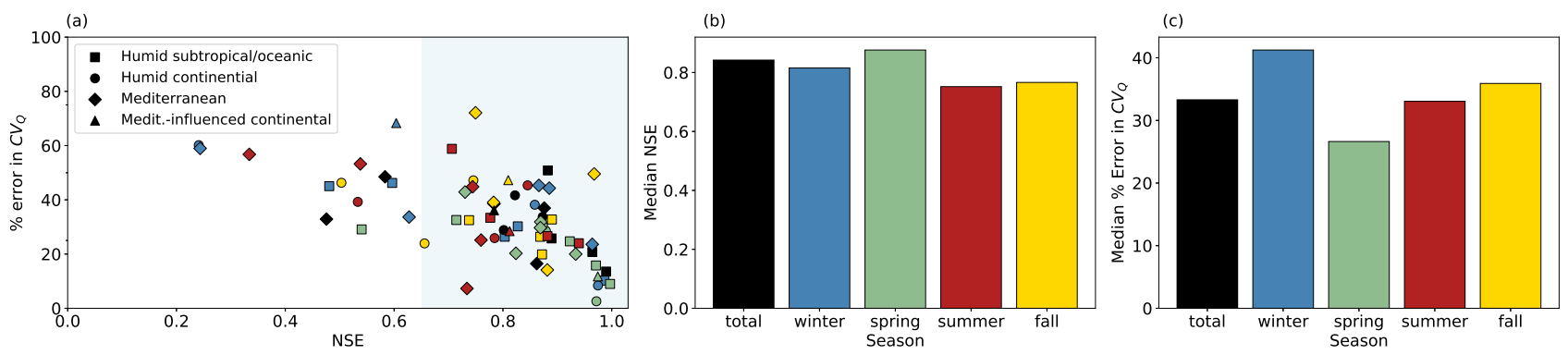

Figure B1. For some sites, seasonal timeseries are better fit by a gamma distribution than the full timeseries. (a) Relationship between NSE and \% error in $C V_{Q}$ for all sites by season. NSE (b) and \% error in $C V_{Q}$ (c) have seasonal relationships, both with best fit shown for spring, although total timeseries are generally fit well. Scatter plot colors in (a) correspond to the bar colors in (b) and (c). 


\section{References}

Abramowitz, M. and Stegun, I. A.: Handbook of mathematical functions with formulas, graphs, and mathematical tables, vol. 55, US Government printing office, 1948.

Acuña, V., Muñoz, I., Giorgi, A., Omella, M., Sabater, F., and Sabater, S.: Drought and postdrought recovery cycles in an intermittent Mediterranean stream: structural and functional aspects, Journal of the North American Benthological Society, 24, 919-933, 2005.

Acuña, V., Datry, T., Marshall, J., Barceló, D., Dahm, C. N., Ginebreda, A., McGregor, G., Sabater, S., Tockner, K., and Palmer, M.: Why should we care about temporary waterways?, Science, 343, 1080-1081, 2014.

Allen, G. H. and Pavelsky, T. M.: Global extent of rivers and streams, Science, 361, 585-588, https://doi.org/10.1126/science.aat0636, publisher: American Association for the Advancement of Science Section: Report, 2018.

Arismendi, I., Dunham, J. B., Heck, M. P., Schultz, L. D., and Hockman-Wert, D.: A Statistical Method to Predict Flow Permanence in Dryland Streams from Time Series of Stream Temperature, Water, 9, 946, number: 12 Publisher: Multidisciplinary Digital Publishing Institute, 2017.

Barefoot, E., Pavelsky, T. M., Allen, G. H., Zimmer, M. A., and McGlynn, B. L.: Temporally Variable Stream Width and Surface Area Distributions in a Headwater Catchment, Water Resources Research, 55, 7166-7181, https://doi.org/10.1029/2018WR023877, _eprint: https://agupubs.onlinelibrary.wiley.com/doi/pdf/10.1029/2018WR023877, 2019.

Beitinger, T. L., Bennett, W. A., and McCauley, R. W.: Temperature tolerances of North American freshwater fishes exposed to dynamic changes in temperature, Environmental biology of fishes, 58, 237-275, 2000.

Bhamjee, R. and Lindsay, J. B.: Ephemeral stream sensor design using state loggers, Hydrology and Earth System Sciences, 15, 1009-1021, https://doi.org/https://doi.org/10.5194/hess-15-1009-2011, publisher: Copernicus GmbH, 2011.

Bishop, K., Buffam, I., Erlandsson, M., Fölster, J., Laudon, H., Seibert, J., and Temnerud, J.: Aqua Incognita: the unknown headwaters, Hydrological Processes, 22, 1239-1242, https://doi.org/10.1002/hyp.7049, _eprint: https://onlinelibrary.wiley.com/doi/pdf/10.1002/hyp.7049, 2008.

Biswal, B. and Marani, M.: Geomorphological origin of recession curves, Geophysical Research Letters, 37, https://doi.org/10.1029/2010GL045415,_eprint: https://agupubs.onlinelibrary.wiley.com/doi/pdf/10.1029/2010GL045415, 2010.

Blyth, K. and Rodda, J.: A stream length study, Water Resources Research, 9, 1454-1461, 1973.

Botter, G. and Durighetto, N.: The Stream Length Duration Curve: a tool for characterizing the time variability of the flowing stream length, Water Resources Research, n/a, e2020WR027 282, https://doi.org/10.1029/2020WR027282, _eprint: https://agupubs.onlinelibrary.wiley.com/doi/pdf/10.1029/2020WR027282, 2020.

Botter, G., Porporato, A., Rodriguez-Iturbe, I., and Rinaldo, A.: Basin-scale soil moisture dynamics and the probabilistic characterization of carrier hydrologic flows: Slow, leaching-prone components of the hydrologic response, Water Resources Research, 43, https://doi.org/10.1029/2006WR005043,_eprint: https://onlinelibrary.wiley.com/doi/pdf/10.1029/2006WR005043, 2007.

Botter, G., Basso, S., Rodriguez-Iturbe, I., and Rinaldo, A.: Resilience of river flow regimes, Proceedings of the National Academy of Sciences, 110, 12 925-12 930, https://doi.org/10.1073/pnas.1311920110, iSBN: 9781311920119 Publisher: National Academy of Sciences Section: Physical Sciences, 2013.

Brooks, R. T.: Potential impacts of global climate change on the hydrology and ecology of ephemeral freshwater systems of the forests of the northeastern United States, Climatic Change, 95, 469-483, 2009. 
Dodds, W. K., et al.: What's in a Name? Patterns, Trends, and Suggestions for Defining Non-Perennial Rivers and Streams, Water, 12 , $1980,2020$.

Castellarin, A., Galeati, G., Brandimarte, L., Montanari, A., and Brath, A.: Regional flow-duration curves: reliability for ungauged basins, Advances in Water Resources, 27, 953-965, 2004.

Chen, D. and Chen, H. W.: Using the Köppen classification to quantify climate variation and change: An example for 1901-2010, Environmental Development, 6, 69-79, 2013.

Clarke, A., Mac Nally, R., Bond, N., and Lake, P. S.: Flow permanence affects aquatic macroinvertebrate diversity and community structure in three headwater streams in a forested catchment, Canadian Journal of Fisheries and Aquatic Sciences, 67, 1649-1657, 2010.

Costigan, K. H., Jaeger, K. L., Goss, C. W., Fritz, K. M., and Goebel, P. C.: Understanding controls on flow permanence in intermittent rivers to aid ecological research: integrating meteorology, geology and land cover, Ecohydrology, 9, 1141-1153, https://doi.org/10.1002/eco.1712,_eprint: https://onlinelibrary.wiley.com/doi/pdf/10.1002/eco.1712, 2016.

Datry, T., Larned, S. T., and Scarsbrook, M. R.: Responses of hyporheic invertebrate assemblages to large-scale variation in flow permanence and surface-subsurface exchange, Freshwater Biology, 52, 1452-1462, 2007.

Day, D. G.: Drainage density changes during rainfall, Earth Surface Processes, 3, 319-326, https://doi.org/10.1002/esp.3290030310, 1978.

Day, D. G.: Drainage density variability and drainage basin outputs, Journal of Hydrology (New Zealand), 22, 3-17, publisher: New Zealand Hydrological Society, 1983.

Day, L. D., Collins, M. E., and Washer, N. E.: Landscape Position and Particle-size Effects on Soil Phosphorus Distributions, Soil Science Society of America Journal, 51, 1547-1553, https://doi.org/10.2136/sssaj1987.03615995005100060026x, $00029,1987$.

Deal, E., Braun, J., and Botter, G.: Understanding the role of rainfall and hydrology in determining fluvial erosion efficiency, Journal of Geophysical Research: Earth Surface, 123, 744-778, 2018.

Defrance, D., Catry, T., Rajaud, A., Dessay, N., and Sultan, B.: Impacts of Greenland and Antarctic Ice Sheet melt on future Köppen climate zone changes simulated by an atmospheric and oceanic general circulation model, Applied Geography, 119, 2020.

Durighetto, N., Vingiani, F., Bertassello, L. E., Camporese, M., and Botter, G.: Intraseasonal Drainage Network Dynamics in a Headwater Catchment of the Italian Alps, Water Resources Research, 56, e2019WR025 563, https://doi.org/10.1029/2019WR025563, 2020.

Edwards, P. J. and Wood, F.: Fernow Experimental Forest daily streamflow, https://doi.org/https://doi.org/10.2737/RDS-2011-0015, updated 9 January 2020, 2011.

Godsey, S. E. and Kirchner, J. W.: Dynamic, discontinuous stream networks: hydrologically driven variations in active drainage density, flowing channels and stream order, Hydrological Processes, 28, 5791-5803, https://doi.org/10.1002/hyp.10310, $00010,2014$.

Goodrich, D. C., Kepner, W. G., Levick, L. R., and Wigington, P. J.: Southwestern Intermittent and Ephemeral Stream Connectivity, JAWRA Journal of the American Water Resources Association, 54, 400-422, https://doi.org/10.1111/1752-1688.12636, _eprint: https://onlinelibrary.wiley.com/doi/pdf/10.1111/1752-1688.12636, 2018.

Gregory, K. J. and Walling, D. E.: The Variation of Drainage Density Within a Catchment, International Association of Scientific Hydrology. Bulletin, 13, 61-68, https://doi.org/10.1080/02626666809493583, publisher: Taylor \& Francis _eprint: https://doi.org/10.1080/02626666809493583, 1968.

Hale, R. L. and Godsey, S. E.: Dynamic stream network intermittence explains emergent dissolved organic carbon chemostasis in headwaters, Hydrological Processes, 33, 1926-1936, https://doi.org/10.1002/hyp.13455, _eprint: https://onlinelibrary.wiley.com/doi/pdf/10.1002/hyp.13455, 2019. 
Harman, C. J., Troch, P. A., and Sivapalan, M.: Functional model of water balance variability at the catchment scale: 2. Elasticity of fast and slow runoff components to precipitation change in the continental United States, Water Resources Research, 47, https://doi.org/10.1029/2010wr009656, http://dx.doi.org/10.1029/2010WR009656, 2011.

Hooshyar, M., Kim, S., Wang, D., and Medeiros, S. C.: Wet channel network extraction by integrating LiDAR intensity and elevation data, Water Resources Research, 51, 10029-10046, https://doi.org/10.1002/2015WR018021, _eprint: https://agupubs.onlinelibrary.wiley.com/doi/pdf/10.1002/2015WR018021, 2015.

Horne, A. C., Nathan, R., Poff, N. L., Bond, N. R., Webb, J. A., Wang, J., and John, A.: Modeling flow-ecology responses in the anthropocene: challenges for sustainable riverine management, BioScience, 69, 789-799, 2019.

Hunsaker, C.: SSCZO - Streamflow / Discharge - KREW, Bull Creek - 2003-2010), https://doi.org/http://www.hydroshare.org/resource/d6d8b2a6e560462 updated 21 November 2019, 2019a.

Hunsaker, C.: SSCZO - Streamflow / Discharge - Providence - (2003-2010), https://doi.org/https://www.hydroshare.org/resource/180f67282b4149ca8d4f updated 21 November 2019, 2019b.

Jensen, C. K., McGuire, K. J., and Prince, P. S.: Headwater stream length dynamics across four physiographic provinces of the Appalachian Highlands, Hydrological Processes, 31, 3350-3363, https://doi.org/10.1002/hyp.11259, _eprint: https://onlinelibrary.wiley.com/doi/pdf/10.1002/hyp.11259, 2017.

Kingston, D. G., Todd, M. C., Taylor, R. G., Thompson, J. R., and Arnell, N. W.: Uncertainty in the estimation of potential evapotranspiration under climate change, Geophysical Research Letters, 36, 2009.

505 Köppen, V.: attempt to classify the climates, preferably according to their relationships with the plant world, geographic journal, 6, 593-611, 1900.

Köppen, W. and Geiger, R.: manual of climatology, vol. 1, Gebrüthe Borntraeger Berlin, 1930.

Lovill, S. M., Hahm, W. J., and Dietrich, W. E.: Drainage from the Critical Zone: Lithologic Controls on the Persistence and Spatial Extent of Wetted Channels during the Summer Dry Season, Water Resources Research, 54, 5702-5726, https://doi.org/10.1029/2017WR021903, _eprint: https://agupubs.onlinelibrary.wiley.com/doi/pdf/10.1029/2017WR021903, 2018.

Lytle, D. A. and Poff, N. L.: Adaptation to natural flow regimes, Trends in ecology \& evolution, 19, 94-100, 2004.

Meerveld, H. J. I. v., Kirchner, J. W., Vis, M. J. P., Assendelft, R. S., and Seibert, J.: Expansion and contraction of the flowing stream network alter hillslope flowpath lengths and the shape of the travel time distribution, Hydrology and Earth System Sciences, 23, 4825-4834, https://doi.org/https://doi.org/10.5194/hess-23-4825-2019, publisher: Copernicus GmbH, 2019.

515 Miniat, C. F., Laseter, S. H., Swank, W. T., and Vose, J. M.: Daily streamflow data for watersheds at Coweeta Hydrologic Lab, North Carolina, https://doi.org/10.2737/RDS-2016-0025, updated 10 February 2020, 2016.

Mouquet, N., Gravel, D., Massol, F., and Calcagno, V.: Extending the concept of keystone species to communities and ecosystems, Ecology Letters, 16, 1-8, 2013.

Müller, M. F., Dralle, D. N., and Thompson, S. E.: Analytical model for flow duration curves in seasonally dry climates, Water Resources Research, 50, 5510-5531, 2014.

Muneepeerakul, R., Azaele, S., Botter, G., Rinaldo, A., and Rodriguez-Iturbe, I.: Daily streamflow analysis based on a two-scaled gamma pulse model, Water Resources Research, 46, 2010.

Poff, N. L., Tokar, S., and Johnson, P.: Stream hydrological and ecological responses to climate change assessed with an artificial neural network, Limnology and Oceanography, 41, 857-863, 1996. 
Prancevic, J. P. and Kirchner, J. W.: Topographic Controls on the Extension and Retraction of Flowing Streams, Geophysical Research Letters, 46, 2084-2092, https://doi.org/10.1029/2018GL081799, _eprint: https://agupubs.onlinelibrary.wiley.com/doi/pdf/10.1029/2018GL081799, 2019.

Ritter, A. and Muñoz-Carpena, R.: Performance evaluation of hydrological models: Statistical significance for reducing subjectivity in goodness-of-fit assessments, Journal of Hydrology, 480, 33-45, 2013.

Roberts, M. C. and Archibold, O. W.: Variation of Drainage Density in a Small British Columbia Watershed1, JAWRA Journal of the American Water Resources Association, 14, 470-476, https://doi.org/10.1111/j.1752-1688.1978.tb02183.x, _eprint: https://onlinelibrary.wiley.com/doi/pdf/10.1111/j.1752-1688.1978.tb02183.x, 1978.

Roberts, M. C. and Klingeman, P. C.: The relationship of drainage net fluctuation and discharge, in: Proc. Internat. Geographical Congress, pp. 181-91, 1972.

Sabo, J. L., Finlay, J. C., Kennedy, T., and Post, D. M.: The role of discharge variation in scaling of drainage area and food chain length in rivers, science, 330, 965-967, 2010.

Seneviratne, S., Nicholls, N., Easterling, D., Goodess, C., Kanae, S., Kossin, J., Luo, Y., Marengo, J., McInnes, K., Rahimi, M., et al.: Changes in climate extremes and their impacts on the natural physical environment, 2012.

Shaw, S. B.: Investigating the linkage between streamflow recession rates and channel network contraction in a mesoscale catchment in New York state, Hydrological Processes, 30, 479-492, https://doi.org/10.1002/hyp.10626, _eprint: https://onlinelibrary.wiley.com/doi/pdf/10.1002/hyp.10626, 2016.

Stern, H., De Hoedt, G., and Ernst, J.: Objective classification of Australian climates, Australian Meteorological Magazine, 49, 87-96, 2000.

Stubbington, R., England, J., Wood, P. J., and Sefton, C. E. M.: Temporary streams in temperate zones: recognizing, monitoring and restoring transitional aquatic-terrestrial ecosystems, WIREs Water, 4, e1223, https://doi.org/10.1002/wat2.1223, _eprint: https://onlinelibrary.wiley.com/doi/pdf/10.1002/wat2.1223, 2017.

Stähli, M.: Longterm hydrological observatory Alptal (central Switzerland), https://www.envidat.ch/\#/metadata/ longterm-hydrological-observatory-alptal-central-switzerland, updated 10 April 2018, 2018.

Swain, D. L., Langenbrunner, B., Neelin, J. D., and Hall, A.: Increasing precipitation volatility in twenty-first-century California, Nature Climate Change, 8, 427-433, https://doi.org/10.1038/s41558-018-0140-y, 2018.

550 Tonkin, J. D., Poff, N. L., Bond, N. R., Horne, A., Merritt, D. M., Reynolds, L. V., Olden, J. D., Ruhi, A., and Lytle, D. A.: Prepare river ecosystems for an uncertain future, 2019.

UK Centre for Ecology and Hydrology: Ray at Grendon Underwood, https://nrfa.ceh.ac.uk/data/station/meanflow/39017, accessed 29 July 2020,2020 .

US Forest Service: Caspar Creek Experimental Watershed Study, NFC - Tributary North Fork (1963-1995) data, https://doi.org/https://www.fs.fed.us/psw/topics/water/caspar/data/map/nfc.shtml, updated 18 August 1998, 1998a.

US Forest Service: Caspar Creek Experimental Watershed Study, SFC - Tributary South Fork (1963-1995) data, https://doi.org/https://www.fs.fed.us/psw/topics/water/caspar/data/map/sfc.shtml, updated 18 August 1998, $1998 \mathrm{~b}$.

U.S. Geological Survey: Elder C Nr Branscomb CA, https://waterdata.usgs.gov/monitoring-location/11475560/\#parameterCode=00060, accessed 28 July 2020, 2020ah.

560 U.S. Geological Survey: Thompson Creek near Clayton, ID, https://waterdata.usgs.gov/monitoring-location/13297330/\#parameterCode= 00060, accessed 05 August 2020, 2020 bf. 
U.S. Geological Survey: Blackbird Creek near Cobalt, ID, https://waterdata.usgs.gov/monitoring-location/13306336/\#parameterCode= 00060, accessed 05 August 2020, 2020ca.

U.S. Geological Survey: , https://waterdata.usgs.gov/monitoring-location/13313000/\#parameterCode=00060, accessed 29 July 2020, $2020 \mathrm{db}$

U.S. Geological Survey: Meadow Creek near Stibnite, ID, https://waterdata.usgs.gov/monitoring-location/13310850/\#parameterCode= 00060, accessed 29 July 2020, 2020ec.

U.S. Geological Survey: MF Salmon River at Mouth near Shoup, ID, https://waterdata.usgs.gov/monitoring-location/13310199/ \#parameterCode=00060, accessed 29 July 2020, 2020 fe.

U.S. Geological Survey: Sagehen C Nr Truckee CA, https://waterdata.usgs.gov/monitoring-location/10343500/\#parameterCode=00060, accessed 29 July 2020, 2020gd.

U.S. Geological Survey: Sixmile Creek at Bethel Grove NY, https://waterdata.usgs.gov/monitoring-location/04233300/\#parameterCode= 00060, accessed 29 July 2020, 2020hg.

USDA Forest Service, Northern Research Station: Hubbard Brook Experimental Forest: Daily Streamflow by Watershed, 1956 - present, https://portal.edirepository.org/nis/mapbrowse?scope=knb-lter-hbr\&identifier=2, updated 25 June 2020, 2020.

van Meerveld, H. J. I., Kirchner, J. W., Vis, M. J. P., Assendelft, R. S., and Seibert, J.: Expansion and contraction of the flowing stream network alter hillslope flowpath lengths and the shape of the travel time distribution, Hydrology and Earth System Sciences, 23, 48254834, https://doi.org/https://doi.org/10.5194/hess-23-4825-2019, publisher: Copernicus GmbH, 2019.

Ward, A. S., Schmadel, N. M., and Wondzell, S. M.: Simulation of dynamic expansion, contraction, and connectivity in a mountain stream network, Advances in Water Resources, 114, 64-82, https://doi.org/10.1016/j.advwatres.2018.01.018, 2018.

Ward, E. J., Anderson, J. H., Beechie, T. J., Pess, G. R., and Ford, M. J.: Increasing hydrologic variability threatens depleted anadromous fish populations, Global change biology, 21, 2500-2509, 2015.

Whiting, J. A. and Godsey, S. E.: Discontinuous headwater stream networks with stable flowheads, Salmon River basin, Idaho, Hydrological Processes, 30, 2305-2316, 2016 a.

Whiting, J. A. and Godsey, S. E.: Discontinuous headwater stream networks with stable flowheads, Salmon River basin, Idaho, Hydrological Processes, 30, 2305-2316, https://doi.org/10.1002/hyp.10790,_eprint: https://onlinelibrary.wiley.com/doi/pdf/10.1002/hyp.10790, 2016b.

Wigington Jr, P., Moser, T., and Lindeman, D.: Stream network expansion: a riparian water quality factor, Hydrological Processes: An International Journal, 19, 1715-1721, 2005.

Zimmer, M.: Duke Forest Research Watershed Data Archives, https://doi.org/https://doi.org/10.2737/RDS-2016-0025, updated 19 July 2019, 2017.

Zimmer, M. A. and McGlynn, B. L.: Ephemeral and intermittent runoff generation processes in a low relief, highly weathered catchment, Water Resources Research, 53, 7055-7077, https://doi.org/10.1002/2016WR019742, _eprint: https://agupubs.onlinelibrary.wiley.com/doi/pdf/10.1002/2016WR019742, 2017.

Zimmer, M. A. and McGlynn, B. L.: Lateral, Vertical, and Longitudinal Source Area Connectivity Drive Runoff and Carbon Export Across Watershed Scales, Water Resources Research, 54, 1576-1598, https://doi.org/10.1002/2017WR021718,_eprint: https://agupubs.onlinelibrary.wiley.com/doi/pdf/10.1002/2017WR021718, 2018. 